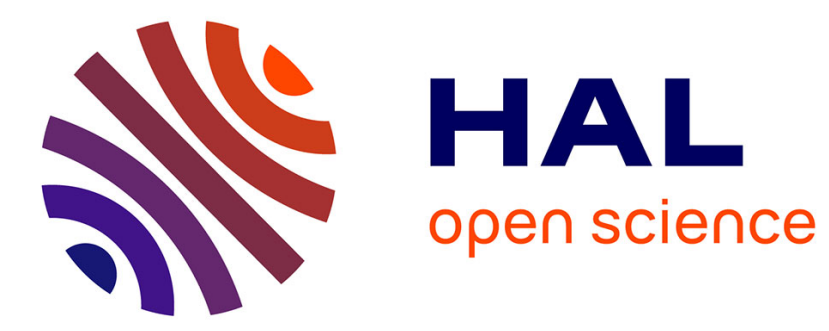

\title{
Temperature variation of ultrasonic attenuation and phase velocity in VO2 and V2o3 crystals
}

\author{
J.Y. Prieur, P. Seznec, S. Ziolkiewicz
}

\section{To cite this version:}

J.Y. Prieur, P. Seznec, S. Ziolkiewicz. Temperature variation of ultrasonic attenuation and phase velocity in VO2 and V2o3 crystals. Journal de Physique Lettres, 1977, 38 (1), pp.25-28. 10.1051/jphyslet:0197700380102500 . jpa-00231314

\section{HAL Id: jpa-00231314 https://hal.science/jpa-00231314}

Submitted on 1 Jan 1977

HAL is a multi-disciplinary open access archive for the deposit and dissemination of scientific research documents, whether they are published or not. The documents may come from teaching and research institutions in France or abroad, or from public or private research centers.
L'archive ouverte pluridisciplinaire HAL, est destinée au dépôt et à la diffusion de documents scientifiques de niveau recherche, publiés ou non, émanant des établissements d'enseignement et de recherche français ou étrangers, des laboratoires publics ou privés. 


\title{
TEMPERATURE VARIATION OF ULTRASONIC ATTENUATION AND PHASE VELOCITY IN $\mathrm{VO}_{2}$ AND $\mathrm{V}_{2} \mathrm{O}_{3}$ CRYSTALS
}

\author{
J. Y. PRIEUR, P. SEZNEC and S. ZIOLKIEWICZ
}

Laboratoire d'Ultrasons $\left({ }^{*}\right)$, Université Pierre et Marie-Curie, Tour 13, 4 place Jussieu, 75230 Paris Cedex 05, France

(Reçu le 20 septembre 1976, révisé le 2 novembre 1976, accepté le 17 novembre 1976)

\begin{abstract}
Résumé. - Nous étudions les variations de l'atténuation ultrasonore et de la vitesse de phase près de la transition de phase de $\mathrm{VO}_{2}$ et $\mathrm{V}_{2} \mathrm{O}_{3}$. Dans la phase haute température de $\mathrm{VO}_{2}$, nous montrons qu'elles sont compatibles avec l'existence d'un mode mou au point $\mathbf{R}$ de la zone de Brillouin. Les forces d'interaction doivent être à longue portée.
\end{abstract}

Abstract. - We report measurements of the change in the ultrasonic attenuation and phase velocity in the vicinity of the phase transitions of $\mathrm{VO}_{2}$ and $\mathrm{V}_{2} \mathrm{O}_{3}$. We show that there exists a variation of the attenuation and of the velocity in the high temperature phase of $\mathrm{VO}_{2}$ which is compatible with the existence of a soft-mode at the R-point of the Brillouin zone. The forces involved should be long-ranged.

There has been much interest during the last few years in the vanadium oxides mainly as a result of the fact that most of them show a metal-insulator transition. This is the case for $\mathrm{V}_{2} \mathrm{O}_{3}$ at $155 \mathrm{~K}$ and for $\mathrm{VO}_{2}$ at $341 \mathrm{~K}$. In both cases, a superimposed crystallographic transition appears. Thus it is not evident whether the electronic transition is due to the lattice one and can be explained by ordinary band theory or, on the contrary, if the electronic transition drives the distorsion and will thus be an example of a Mott transition.

The state of the controversy is quite different for the two compounds. In $\mathrm{V}_{2} \mathrm{O}_{3}$, it is generally believed that the transition results from the ordering of the magnetic moments, the crystallographic distortion being due to the magnetostriction [1, 2]. The entropy of the metallic phase is mainly due to the free electron system.

However in Vanadium dioxide, the most important part of the entropy comes from the phonon system. Paul [3] and Goodenough [4] suggested that the transition is caused by a lattice distorsion which splits a band called " $d_{\|}$" into two parts and which at the same time elevates the energy of another overlapping band called " $\pi^{*}$ ». Sommers et al. [5] showed that this mechanism was not strong enough to give rise to a gap of $0.6 \mathrm{eV}$ as observed by $\mathrm{H}$. W. Verleur et al. [6]. Zylbersztejn and Mott [7] proposed a new model taking explicitly into account the Hubbard

(*) Associated with the Centre National de la Recherche Scientifique. energy which should be unscreened by the rising of the $\pi^{*}$ band. Nevertheless a distortion is necessary to initiate the transition and, in this sense, we could say it drives the transition.

Ultrasonic waves are often used to study phase transitions. For example, Testardi [8] extensively investigated the martensitic transition in the A 15 compounds. Bachellerie and Frénois [9] studied the antiferromagnetic paramagnetic transition of $\mathrm{Cr}_{2} \mathrm{O}_{3}$. Courdille and Dumas [10] and Melcher and Scott [11] observed structural phase transitions in $\mathrm{Gd}_{2}\left(\mathrm{MoO}_{4}\right)_{3}$ and $\mathrm{DyVO}_{4}$ respectively. It seemed to us worthwhile to apply ultrasonic techniques to the study of $\mathrm{V}_{2} \mathrm{O}_{3}$ and $\mathrm{VO}_{2}$. We could hope to see if there are any excitations which become soft near the transition.

There have been many attempts to observe such excitations by other techniques. Srivasta and Chase [12] performed Raman experiments; they did not observe any soft modes in the low temperature phase where the modes are sharp. In the high temperature range, the modes are so broadened by electron-phonon interaction that it was impossible to obtain any information.

We will now present our experimental technique and results. Standard techniques, were used to measure the variations of the attenuation and phase velocity of an ultrasonic wave propagating through a sample of $\mathrm{VO}_{2}$ or $\mathrm{V}_{2} \mathrm{O}_{3}$ as a function of temperature. At the same time, we took care to follow the variations of the resistivity by applying electrodes on the sides of the crystal.

We used both transverse and longitudinal waves for 
this study. The ultrasonic wave propagated along the $a$ - or the $c$-crystallographic directions for $\mathrm{V}_{2} \mathrm{O}_{3}$, and only along the two-fold axis of $\mathrm{VO}_{2}$ because it is the only simple direction for pure mode propagation in the monoclinic phase.

In all our experiments, the temperature was varied very slowly when approaching the transition. A typical rate was $10^{-3} \mathrm{~K}$ per minute within $1 \mathrm{~K}$ of the critical temperature. In $\mathrm{V}_{2} \mathrm{O}_{3}$, we never succeeded in going through the transition without breaking the crystal. We tried (without success) to prevent the breaking of the sample by applying an uniaxial stress along the $a$-direction of the high temperature phase. In $\mathrm{VO}_{2}$, we could pass the transition from the low temperature phase to the high temperature one but never in the reverse direction.

The crystals of $\mathrm{V}_{2} \mathrm{O}_{3}$ were grown in our laboratory by using the technique of Faguel and Grajower [13]. For $\mathrm{VO}_{2}$, the crystals were grown at the Laboratoire Central de Recherche, Thomson-C.S.F., by P. Merenda. Typical resistivity jumps were $10^{4}$ in $\mathrm{V}_{2} \mathrm{O}_{3}$ and $10^{5}$ in $\mathrm{VO}_{2}$. The crystal dimensions were of the order of $1 \mathrm{~mm} \times 1 \mathrm{~mm} \times 1 \mathrm{~mm}$.

The results are shown for $\mathrm{V}_{2} \mathrm{O}_{3}$ in figure 1 . We did not observe any critical variation of the attenuation or phase velocity before the transition. The monotonic smooth variation is due partly to the bonding material and partly to a normal temperature dependence of the elastic constants of $\mathrm{V}_{2} \mathrm{O}_{3}$.

For $\mathrm{VO}_{2}$, the results are displayed in figures 2, 3 and 4. In figure 2, a general picture of the measurements is given. Both the variation of the attenuation for

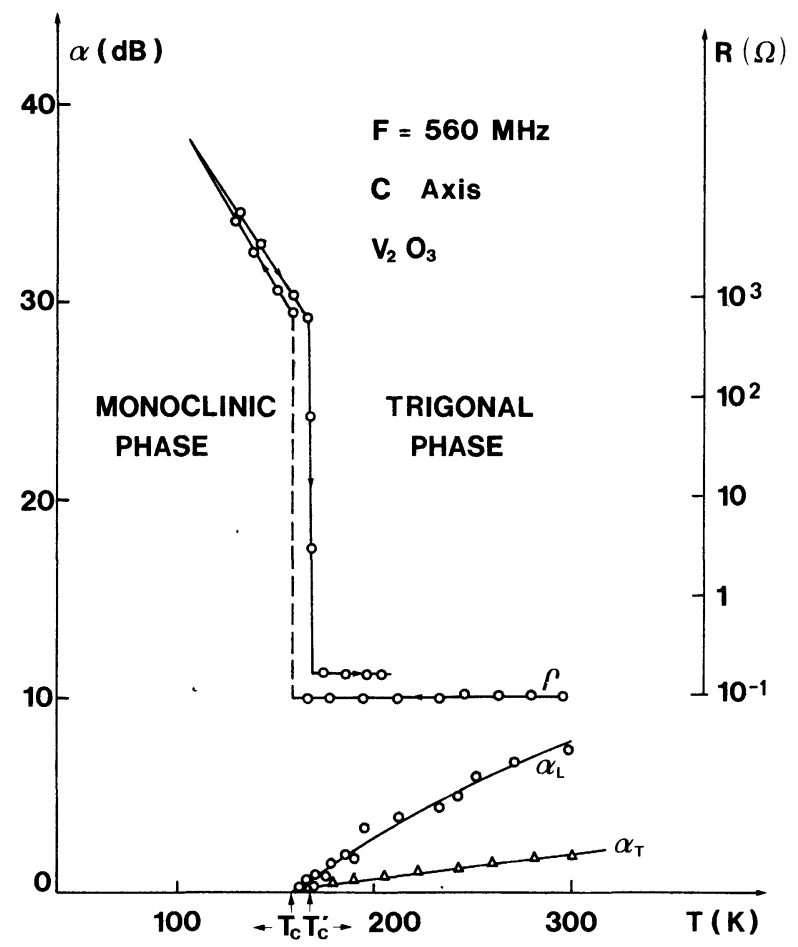

FIG. 1. - Longitudinal and transverse attenuation variation in a $0.73 \mathrm{~mm}$ thick $\mathrm{V}_{2} \mathrm{O}_{3}$ sample at $560 \mathrm{MHz}$ and along the $c$-axis. In the upper part the resistivity variations are shown. longitudinal and transverse waves are shown for the frequency of $560 \mathrm{MHz}$. There is a critical variation for both types of waves in the high temperature range, but only for transverse waves on the low temperature side.

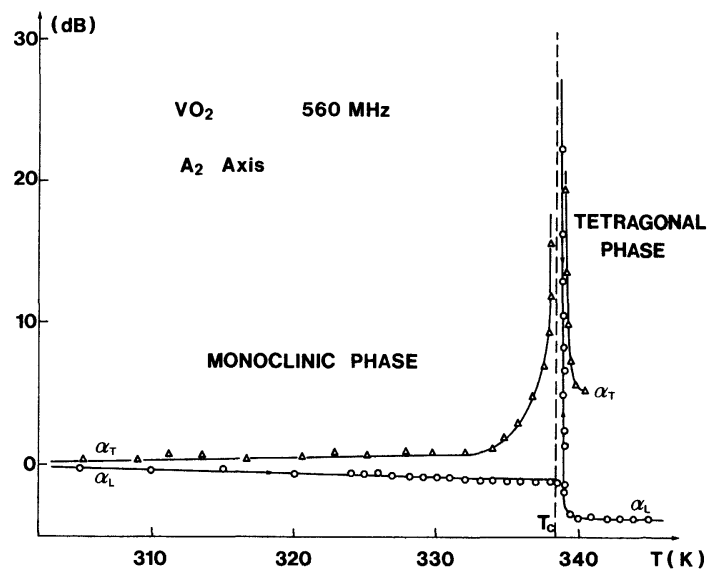

FIG. 2. - General picture of the variations of the longitudinal and transverse acoustic waves along the two-fold axis of a $\mathrm{VO}_{2}$ crystal at $560 \mathrm{MHz}$.

In figure 3, the details of the attenuation and variation of the phase velocity are shown for longitudinal waves in the high temperature domain for decreasing temperatures. Note that the phase and attenuation variations appear at exactly the same temperatures for the first ten high temperature points. This rules out the hypothesis that the increments of the attenuation observed in this temperature range are due to a partly broken crystal.

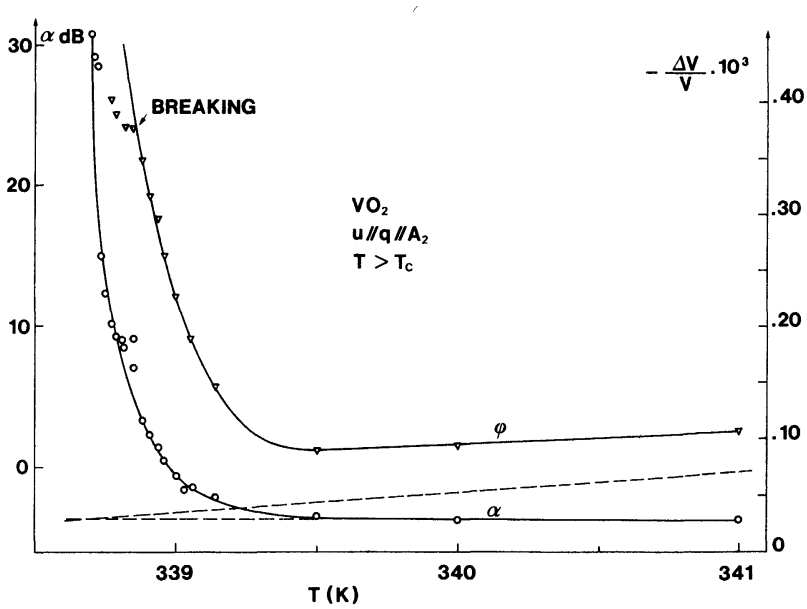

FIG. 3. - Detailed behaviour of the decrease in the velocity and the increase in the attenuation of a longitudinal wave propagating along the two-fold axis of a $\mathrm{VO}_{2}$ crystal in the high temperature phase. Note the breaking point of the crystal.

Finally, figure 4 shows the result of a fit of the experimental measurements on a Log-Log plot to a straight line. Note that we used only the ten high temperature points of figure 3 , because the eleventh point shows a large variation of the attenuation but no corresponding variation of the phase velocity indi- 


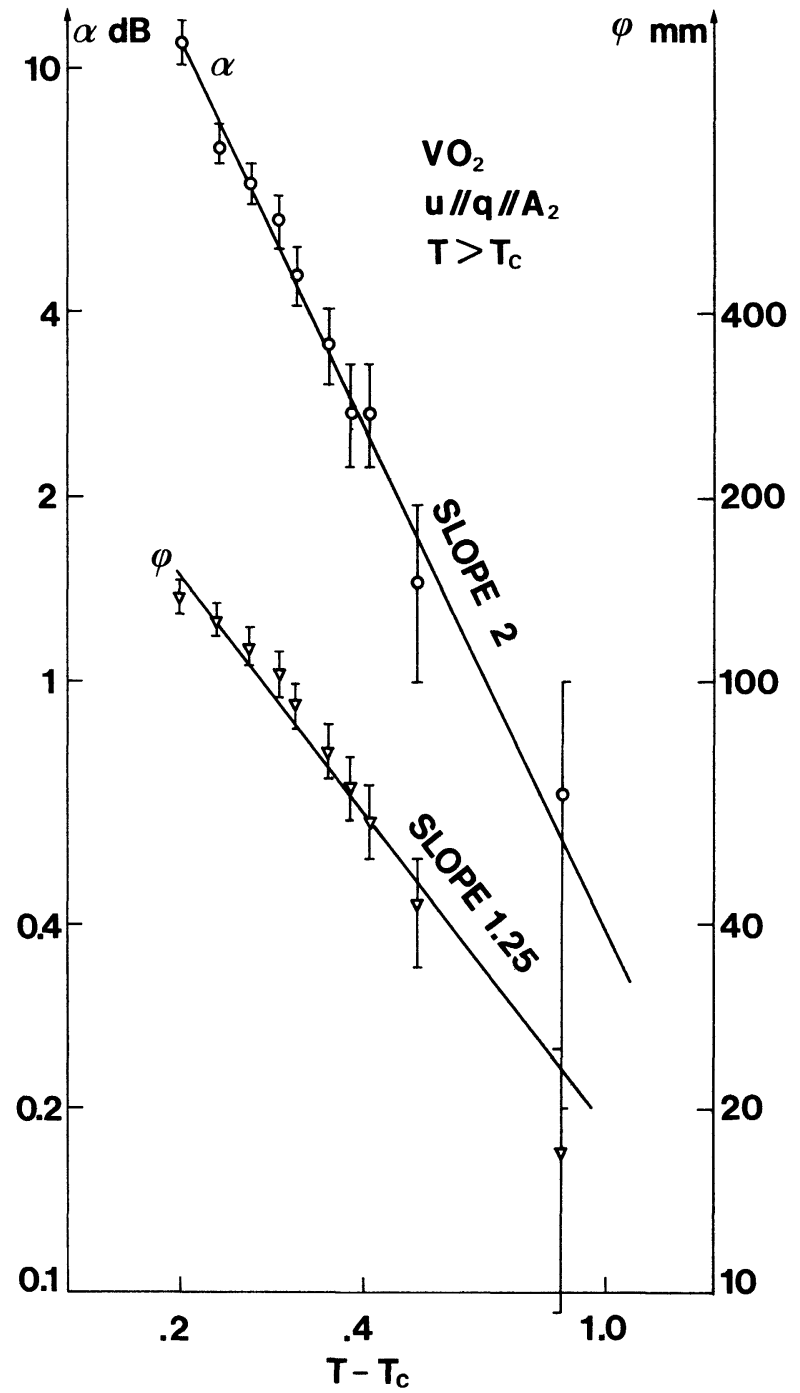

FIG. 4. - Graphical determination of the critical exponents of the measurements in figure 3 . The slopes of the straight lines are 1.25 and 2.

cating that the crystal is beginning to break. For the fit we used two parameters : the non-critical part of the attenuation (or phase variation) and the temperature $T$ of the pole of the critical part of the susceptibility. Of course, the same pole temperature has been used for the attenuation and velocity curves. We found :

$$
T_{0}=(338.6 \pm 0.1) \mathrm{K}
$$

The slopes of the lines are a measure of the corresponding critical exponents.

We write :

$$
\begin{array}{ll}
\alpha_{\mathrm{c}} \sim\left(T-T_{0}\right)^{-m} & \text { with } \quad m=2 \pm 0.25 \\
\varphi_{\mathrm{c}} \sim\left(T-T_{0}\right)^{-n} & \text { with } \quad n=1.25 \pm 0.25 .
\end{array}
$$

Of course, the accuracy is not very good because the first order nature of the transition prevents us from observing more than one decade of $\left(T-T_{0}\right)$.

We shall discuss now the experimental results.
There is not much to say about $\mathrm{V}_{2} \mathrm{O}_{3}$ because we do not observe any critical variation. However, we can compare this with what has been observed previously in $\mathrm{Cr}_{2} \mathrm{O}_{3}$ at the Néel transition. Bachellerie and Frénois [9] have observed a critical variation of the attenuation and phase velocity due to the coupling with the magnetic fluctuations. But, due to the long range nature of the forces in $\mathrm{Cr}_{2} \mathrm{O}_{3}$, the critical range in their experiments was very narrow $(0.05 \mathrm{~K})$. Thus it is not surprising that in our case of a first order transition we are not able to detect any critical variation.

In a theoretical analysis of $\mathrm{VO}_{2}, \mathrm{~J}$. R. Brews [14] showed that if there are one or more soft phonons modes, these modes should be localised at the R-point of the Brillouin zone of the high temperature phase. At this point, there are only two different symmetries for the space group of rutile. Brews also showed that the vanadium atomic displacements are compatible with only one of these symmetries. It is easy to show, from group theory, that the ultrasonic waves are coupled to soft phonons for any symmetry of the wave or of the soft modes [15]. In other words, there are no selection rules. In figure 2 , we can see that both types of waves have a critical variation in the high temperature range as expected.

In the low temperature region, however, only transverse waves have a critical variation. It has been suggested that, in this range of temperature, some islands of the metallic phase are growing due to inhomogeneous material [16] or due to an inhomogeneous temperature [17]. If the dimensions of the islands were of the order of the ultrasonic wavelength or bigger, the wave front would become distorted and interference effects would be observed as a function of temperature; this is not borne out by the experiments. Thus we can assume that the islands, if they are important, are much smaller than the wavelength in which case the attenuation should have a Rayleigh diffusion characteristic ( $\omega^{4}$ dependence). This we also do not observe. Finally, for the case where the islands are caused by inhomogeneities in the temperature, the range of temperatures over which effects are observed is dependent on the rate at which the temperature is varied [17]. We do not observe this possibly because the rate of change of the temperature is very slow in our experiments. We ruled therefore out this hypothesis. It might also be expected that the variation could be due to interaction with soft optic modes. However, group theory shows that only longitudinal waves should be affected [18], ruling out that hypothesis as well. On the other hand, a possible explanation is that the critical variation could result from domains, which in $\mathrm{VO}_{2}$ are orientated at $90^{\circ}$ to each other. It is not surprising that only transverse waves see the domains because generally the elastic constants are more isotropic for longitudinal waves than for transverse ones. Thus the former will be less affected than the latter when going from propagation 
along the binary axis to propagation in the symmetry plane. Alternately, we suggest that the attenuation may be due to the existence of an unstable acoustic mode of the symmetry $\Gamma_{2}^{+}$as for the $\Gamma_{3}^{+}$mode in the A 15 compound at the martensitic transition [8]. In our case, longitudinal waves have $\Gamma_{1}^{+}$symmetry and do not couple to the unstable mode. The best way to decide which of these two mechanisms applies is probably to look for instabilities by Brillouin scattering.

The critical exponents for the longitudinal waves are compatible with those we can deduce from a Landau theory of critical attenuation and phase velocity for an overdamped mode with a bidimensional dispersion in the wave-vector space. The theoretical exponents are [19] :

$$
m=2, \quad n=1 .
$$

The bidimensional nature of the atomic fluctuations has been observed independently by Comès et al. [20] by diffuse $\mathrm{X}$-ray scattering.

Finally, we compare the temperature width of the critical regime to the ones which appear in other displacive transitions. For $\mathrm{VO}_{2}$, this width is only $0.5 \mathrm{~K}$, as compared to $50 \mathrm{~K}$ for $\mathrm{Gd}_{2}\left(\mathrm{MoO}_{4}\right)_{3}[10], 160 \mathrm{~K}$ for $\mathrm{DyVO}_{4}$ [11] and $30 \mathrm{~K}$ in $\mathrm{SrTiO}_{3}$ [21]. We know that the width is fixed by two quantities, the coupling factor, and the range of the forces.
The coupling factor can explain the different widths for $\mathrm{Gd}_{2}\left(\mathrm{MoO}_{4}\right)_{3}, \mathrm{SrTiO}_{3}$ and $\mathrm{DyVO}_{4}$ because for the last one, we have a strong coupling (first order in order parameter) and weak coupling for the two others (second order in order parameter). But in the case of $\mathrm{VO}_{2}$, where the coupling is also weak, the order of magnitude of the width of the critical zone is quite different from that of $\mathrm{SrTiO}_{3}$ and can only be explained by a long range of the forces as in the case of $\mathrm{Cr}_{2} \mathrm{O}_{3}$. Usually the range is of the order of one interactomic distance (nearest neighbour interaction). The forces cannot be interatomic in $\mathrm{VO}_{2}$ but Coulombic to explain so large an interaction length. For the same reason, if the hypothesis of acoustic instabilities is true in the low temperature phase, the forces driving these instabilities should be long range.

In summary, we observed by an ultrasonic technique a critical variation of the attenuation and phase velocity in vanadium dioxide. From the value of the critical exponent, we showed that the associated fluctuations are bidimensional and from the width of the critical regime, we conclude that the forces which drive the transition are long range. We think the fluctuations are due to atomic motion but we cannot decide if they must be associated with vanadium or oxygen atoms : it is natural to attribute the fluctuations to the vanadium atoms. This is the first clear experimental evidence for the existence of dynamical fluctuations in $\mathrm{VO}_{2}$.

\section{References}

[1] Motr, N., in Metal Insulator Transition (Taylor and Francis, London).

[2] Rice, T. M. and MCWhen, D. B., IBM J. Res. Dev. 14 (1970) 251.

[3] Paul, W., Mater. Res. Bull. 5 (1970) 691.

[4] Goodenough, J. B., J. Solid State Chem. 3 (1971) 490 ; Goodenough, J. B. and Y-P Hong, H., Phys. Rev. B 8 (1973) 1323.

[5] Sommers, C., De Groot, R., KaPlan, D. and Zylbersztejn, A., J. Physique Lett. 36 (1975) L-157.

[6] Verleur, H. W., Barker Jr, A. S. and Berglund, C. N., Phys. Rev. 172 (1968) 788.

[7] Zylbersztejn, A. and Mott, N. F., Phys. Rev. B 11 (1975) 4383.

[8] Testard, L. R., in Physical Acoustics, Vol. X, Ed. Warren P. Mason (Academic Press, New York and London) references thereın.

[9] Bachellerie, A. and FrénoIs, Ch., J. Physique 35 (1974) 437.

[10] Courdille, J. M. and Dumas, J., J. Physique Lett. 36 (1975) L-5.

[11] Melcher, R. L. and Scott, B. A., Phys. Rev. Lett. 28 (1972) 607.

[12] Srivasta, R. and Chase, L. L., Phys. Rev. Lett. 27 (1971) 727. Chase, L. L. and SRIVASTA, R., in Light Scattering in Solids (Paris, M. Balkanski Ed.) 1971, p. 380.

[13] Foguel, M. and Grajowet, R., J. Cryst. Growth 11 (1971) 280.

[14] Brews, J. R., Phys. Rev. B 1 (1970) 2557.

[15] It is necessary to show that a term as $\varepsilon_{x x} \eta^{2}$, or $\varepsilon_{x z} \eta^{2}$ ( $\eta$ is the order parameter) can exist in the hamiltonian : i.e. they are scalars. Because of the non symmorphic nature of the $\mathrm{D}_{4 \mathrm{~h}}^{14}$ group (the high temperature group of $\mathrm{VO}_{2}$ ) the wave vector group at point $\mathrm{R}$ must be associated with the one at the point $\Gamma$ (see Elliotr and London, J. Phys. Chem. Solids 15 (1960) 146). Then taking into account the characters of the representations of the point $R$ [14] (soft mode representations) we can find how $\eta^{2}$ transforms under the symmetrics of the crystal $\left(\left[\mathbf{R}^{+}\right]^{2}\right.$ and $\left[\mathbf{R}^{-}\right]^{2}$ decompose to $\left.\Gamma_{1}^{+} \oplus \Gamma_{2}^{+} \oplus \Gamma_{3}^{+} \oplus \Gamma_{4}^{+}\right)$. Now $\varepsilon_{x x}$ transforms as $\Gamma_{1}^{+}$and $\varepsilon_{x z}$ as $\Gamma_{4}^{+}$. Therefore $\varepsilon_{x x}$ and $\varepsilon_{x z}$ will have a part transforming as $\Gamma_{1}^{+}$q.e.d.

[16] Gerbshtein, Yu. M., Smirnova, T. V., Terukov, E. I. and ChudnovskiI, F. A., Sov. Phys. Solid State 18 (1976) 290.

[17] Zylbersztejn, A., Pannetier, B. and Merenda, P., Phys. Lett. 54A (1975) 145.

[18] If, in the low temperature phase, there are soft optic modes, they will be at the center of the zone where the wave vector group is $C_{2 h}$. There are four representations and the square of each one decomposes as $\Gamma_{1}^{+}$. Now $\varepsilon_{z z}$ transforms as $\Gamma_{1}^{+}$and both $\varepsilon_{z x}$ and $\varepsilon_{z y}$ as $\Gamma_{2}^{+}(z$ is the binary axis). Thus longitudinal waves are coupled and transverse waves are not.

[19] Dumas, J., Thèse, Paris (June 1975) registered at the Centre National de la Recherche Scientifique under the number AO 11422.

[20] Comès, R., Félix, P., Lambert, M. and Villeneuve, G., Acta Crystallogr. A 30 (1974) 55.

[21] Von Waldkirch, Th., Müller, K. A. and Berlinger, W., Phys. Rev. Lett. 28 (1972) 503. 